\title{
La transformación y gentrificación turística del espacio urbano. El caso de la Barceloneta (Barcelona)
}

\author{
Montserrat Crespi-Vallbona. Universidad de Barcelona, Barcelona, España. \\ Óscar Mascarilla-Miró. Universidad de Barcelona, Barcelona, Espańa.
}

RESUMEN | Las áreas urbanas con atractivo turístico viven grandes transformaciones. Uno de los barrios más significativos de Barcelona, histórico emplazamiento de los marineros de la ciudad, es la Barceloneta. En los últimos tiempos, su capacidad para atraer turismo gastronómico y de "sol y playa" ha generado cambios importantes en su estructura social y económica. Para este artículo se observan en tal conversión los elementos que configuran el sistema turístico: alojamiento, recursos y política turística. Las fuentes bibliográficas y hemerográficas (prensa y revistas) conforman la base para la recopilación de la información y de los datos históricos. Finalmente, entrevistas y observación participante completan el análisis. Todo ello permite proyectar un modelo de ciudad funcional y sostenible como espacio objeto y sujeto, tanto para los residentes locales como los visitantes, que decanta en el denominado modelo de conversión turística gentrificada.

PALABRAS CLAVE | morfología urbana, desarrollo sustentable, gentrificación.

ABSTRACT | Urban areas with tourist attractions usually undergo major transformations. One of Barcelona's most significant neighborhoods is called Barceloneta, the historical site of the city's sailors. More recently, this area's capacity to attract gastronomic and beach tourism has generated important changes in the social and economic structure. In this conversion, the typical elements involved in the tourism system are observed: Accommodation, resources and tourism policies. Bibliographic, press and magazine sources form the basis of the collection of information and historical data taken into account for this research. Also, interviews and participant observation complete the analysis. This data allows the projection of a functional and sustainable city model as a space object and subject, both for local residents and visitors, presenting the so-called gentrified tourist conversion model.

KEYWORDS | urban morphology, sustainable development, gentrification. 


\section{Introducción}

Las ciudades son dinámicas y son conflicto por propia definición. Las transformaciones y regeneraciones de los espacios urbanos generalmente se acompañan de procesos de gentrificación (Beauregard, 1985; Lees, Slater \& Wyly, 2008) y de cambios en las actividades comerciales y en el paisaje urbano (Janoschka, Sequera \& Salinas, 2013), basados en el turismo y el patrimonio cultural (Hiernaux, 2006; Vergara \& Casellas, 2016). Barcelona, y concretamente el barrio de la Barceloneta, no son ninguna excepción. El análisis de los cambios en su morfología urbana inicial revela un barrio privilegiado por su situación frente al mar, deseado para vivir por parte de los vecinos, y buscado para tener una experiencia memorable por los turistas. La Barceloneta goza de playas emblemáticas - la de Somorrostro, Barceloneta y Sant Sebastià-, que atraen a un elevado número de visitantes. Y con ello, desde 2014 surgen los conflictos con los vecinos.

Como consecuencia de su desarrollo residencial y turístico, la gentrificación ha alcanzado de lleno al barrio. El auge de las redes sociales ha atraído un público distinto de la población local y ha creado nuevas formas de producción de bienes y servicios, incentivando el crecimiento de la actividad turística. El turismo es una fuente de oportunidades e ingresos que contribuye a la transformación urbana; pero esta es, a la vez, una conversión que puede despojar a una comunidad -su patrimonio tangible e intangible y su calidad de vida- de la singularidad, alma y autenticidad que la definen. En vistas de tal posibilidad, el principal objetivo de este artículo es examinar la posibilidad de compatibilizar ciertas funcionalidades urbanas con una intervención para regenerar la imagen del barrio y atraer otra tipología de visitantes. La ciudad como objeto y también como sujeto.

Para desarrollar los temas seńalados, el artículo se estructura con un primer apartado de revisión de la literatura existente en relación con el desarrollo y gestión de los destinos turísticos. A continuación se realiza una inmersión en la Barceloneta, contextualizándola históricamente y analizando su estructura turística. El apartado de análisis de los resultados detalla los impactos económicos, socioculturales, ambientales y de gestión del destino, para llegar finalmente a la recomendación de un modelo de conversión y gestión de convivencia de los espacios urbanos y turísticos. La tensión entre un comportamiento incívico generalizado de los visitantes; los precios de los inmuebles, inaccesibles para la población tradicional del barrio; y la aglomeración de personas en las plazas, calles y playas hacen necesaria una reflexión, intervención y reorientación de la administración pública responsable.

Metodológicamente, se analizan distintos planes, informes y políticas turísticas del Ayuntamiento de Barcelona, y datos estadísticos publicados tanto por el Ayuntamiento como por el Departamento de Empresa y Conocimiento de la Generalitat de Cataluña. También se revisa la prensa escrita que se ha hecho eco de la disconformidad de los aspectos descritos. Por último, se ha observado la realidad y la problemática de la Barceloneta con entrevistas y observación directa de los actores implicados. 


\section{Revisión de la literatura científica}

El modelo teórico del ciclo de vida de un destino desarrollado por Butler (1980, 2000) es el marco de referencia que aquí se aplica para el análisis de la evolución de los espacios turísticos. Aunque su modelo es simple, es el más utilizado. Estudia el comportamiento de la demanda y la capacidad de carga de los centros turísticos, considerando la relación positiva entre el incremento del número de visitantes y el desarrollo turístico del área en materia de alojamiento, organización y propiedad de los atractivos y servicios turísticos; los impactos socioculturales, económicos y medioambientales; la satisfacción de los visitantes, etcétera.

Es en las fases de consolidación y posterior estancamiento de un centro urbano turístico cuando más se precisa de la gobernanza y de planes estratégicos políticos holísticos. El agotamiento e intensidad de estas fases se expresa en distintos términos: ambientales (escasez), sociales (resentimiento de la población local, incivismo de los visitantes), económicos (incremento de precios de los productos básicos y disfunción de la oferta basada exclusivamente en el turismo, desatendiéndose las necesidades de la comunidad local), culturales (cambios en los hábitos y costumbres locales para adaptarse a las necesidades de los visitantes extranjeros) y en la insatisfacción de los visitantes (que perciben el rechazo de la comunidad local, el exceso de turistas o el comportamiento negativo de estos). Las externalidades negativas son mayores que las positivas. La animadversión que suscita el turista se da en paralelo con procesos de gentrificación, materializados en la llegada de gente con mayor capital económico y cultural que desplaza a la población tradicional -es decir, las clases populares más desfavorecidas económicamente, más vulnerables-, hasta el punto de excluirla definitivamente del territorio (Desmond, 2012; González, 2011; Hiernaux, 2006; Janoschka \& Sequera, 2014; Lees et al., 2008). Estos procesos se dan principalmente en el ámbito simbólico y de mercados inmobiliarios, impulsados por la administración local (Janoschka et al., 2013; López-Morales, 2011) y despiertan respuestas de resistencia a la gentrificación (Casgrain \& Janoschka, 2013).

La forma de reconducir esta situación y evitar el declive del destino turístico es la planificación de su conversión, el diseño de planes para la inclusión o recuperación de los turistas alocéntricos (Plog, 1974) o exploradores (Cohen, 1972), la considerada elite del turismo. Ciertamente, cuando el destino se vuelca a una determinada tipología de la demanda, sensible a los bajos precios, a la poca o inexistente oferta de recursos culturales, a la profusión de un determinado tipo de tiendas de souvenirs, etcétera, se genera un rechazo de otros segmentos, de otros perfiles de visitantes. Rejuvenecer, redireccionar y reconducir un destino para que vuelva a ser competitivo obliga a repensar el perfil de los turistas y, por tanto, a incluir y desarrollar nuevos atractivos. Las políticas urbanas proempresariales con un contenido discursivo-ideológico legitiman la transformación y cualificación de espacios decaídos en potencialmente rentables (Weber, 2002), destinados a la inversión privada de capital (Guerrero, 2012; Harvey, 1989; Sobarzo, 2008) y a la posibilidad de agregación de valor al valor, en términos de Bourdieu (1997).

En este sentido, Yunis (2004) señala la necesidad de apostar por la calidad de la oferta frente a la imposible lucha por precios ante la competencia de otros destinos. 
La calidad tiene inherente un contenido; no se trata solo de un sello o etiqueta, se trata de dotar al producto, al servicio, a la experiencia, de un valor añadido y significativo. Se centra en buscar la singularidad, la diferencia, la autenticidad. Huir de la macdonalización para salvar lo genuino (Ritzer, 1996) o de la museificación de espacios de alto valor patrimonial (Carrión, 2010; Nelle, 2009), teniendo en cuenta tanto los aspectos tangibles como los intangibles en la cadena de valor de la satisfacción percibida. En esta tesitura se encuentran las organizaciones que gestionan la actividad turística y que son responsables de diseñar políticas de desarrollo y/o reimpulso del turismo. Sin lugar a dudas, estas propuestas de dinamización se centran en la cultura local, en la idiosincrasia particular de cada destino, en su patrimonio y cotidianeidad. De aquí el valor de preservar lo cotidiano, el patrimonio tangible e intangible, las costumbres y la relevancia de poner en valor la cultura local.

Certeau (1990) afirma que la vida cotidiana es el lugar donde se dan las resistencias a la dominación, es decir, el ámbito que escapa a los mecanismos de poder y que permite que reluzca la idiosincrasia de una comunidad, su carácter más auténtico. Así, Heller (1970) identifica la noción de vida cotidiana como el lugar donde se hace la historia, sin ubicarse fuera de la historia; el ámbito donde la gente reproduce la sociedad, sus relaciones y sus valores hegemónicos, pero también donde crea alternativas, cambio y transformación. Esto es, la apropiación del espacio urbano, la actividad que la gente hace a través de sus prácticas cotidianas, inscribiendo en ese espacio sus valores y significados, rescatándolos y creándolos, configurando modelos de ciudad. Así pues, la gente concreta en contextos concretos construye la ciudad y sus espacios a través de las prácticas de su vida cotidiana.

$\mathrm{Y}$ es ante la invasión del turismo en el espacio urbano cotidiano cuando se evidencia y reivindica con mayor intensidad la necesidad de compatibilizar usos, de buscar la convivencia equilibrada entre sus residentes, los permanentes y los temporales, los ciudadanos y los turistas, los locales y los forasteros. Unos dependen de otros; su necesidad es recíproca. Un barrio posgentrificado, sin vecinos, asimilado a un parque temático, sin singularidad, tiene la misma problemática que un espacio urbano sin ocio nocturno, convertido en un espacio "esterilizado, muerto", puesto que la noche ha sido y sigue siendo el entorno esencial e irrenunciable para crear comunidad (Gwiazdzinski, 2007). Así, se insiste en la necesidad de equilibrio entre los usos y funciones de la ciudad: la residencial, la laboral, la de movilidad, la de esparcimiento... Los retos de las actuales ciudades, principalmente las consolidadas turísticamente, precisan de estrategias urbanas posgentrificadoras y de reconversión del modelo turístico, basado en la autenticidad de la cotidianeidad, el prestigio, el estatus, la singularidad. Un modelo que persigue un turista culto, de poder adquisitivo y viajado, y cuyo comportamiento es (y debe ser) compatible, sostenible con el quehacer diario del residente. Un modelo de turismo sostenible (Liu, 2003; Padin, 2012; Sharpley, 2000) que atiende a sus cuatro dimensiones -medioambiental, económica, social y de gestión del destino- para conseguir la sostenibilidad integral (Clark \& Chabrel, 2007; Saxena Clark, Oliver \& Ilbery, 2007; World Tourism Organization [wто], 2004).

Un turismo sostenible es aquel que en su dimensión social recoge las cuestiones que tienen que ver con el bienestar de la población local, la conservación del 
patrimonio cultural y la participación de la comunidad en el proceso de planificación y desarrollo turístico. En cuanto a la dimensión económica, tiene en cuenta los aspectos relacionados con la viabilidad a largo plazo de la actividad turística como actividad económica. Se trata de aprovechar y consolidar el empleo turístico, los efectos directos e indirectos de la actividad; identificar y diferenciar el destino por una experiencia memorable y una marca propia (Ritchie \& Crouch, 2003), evitando el "monocultivo", el enfoque solo turístico (Chatterton \& Hollands, 2003). En la dimensión ambiental se tratan los aspectos relacionados con la conservación y protección de los recursos y ecosistemas naturales para analizar su viabilidad a largo plazo. Por último, la gestión del destino se centra en cuestiones relacionadas con la satisfacción del visitante, la promoción y comunicación.

\section{El caso de la Barceloneta}

\section{Contextualización histórica}

Hasta mediados del siglo XviII, la Barceloneta era una zona extramuros, poco poblada. Los primeros habitantes eran trabajadores del mar que construyeron barracas para guardar sus utensilios. En poco tiempo, la zona se transformó en uno de los mejores ejemplos de urbanismo barroco español, siguiendo la evolución económica y demográfica de signo alcista, culminando con el crecimiento vertical y fraccionamiento de las viviendas (López \& Grau, 1971): los famosos "cuartos de casa”.

El nacimiento de la Barceloneta se debe a la Guerra de Sucesión (1701-1714) y la consecuente construcción de una fortaleza militar (la Ciutadella) en el espacio ocupado por las viviendas que fueron demolidas. Para albergar a los ciudadanos desalojados, se pensó en ubicarlos en el arenal cercano al mar anteriormente mencionado, fuera de las murallas. Este proyecto no se llevó a cabo de forma inminente, sino años después, a raíz de la creciente actividad del puerto y la recuperación de la economía. En el Archivo Histórico del Ejército se conserva el documento gráfico donde se aprecia su trazado ortogonal, caracterizado por la repetición de un mismo elemento: la manzana larga y estrecha en proporción de 1 a 10, paralela al puerto (Tatger, 1973). En estas manzanas se prescribía edificar casas unifamiliares compuestas de una planta baja y un piso superior. Su aspecto exterior debía ser uniforme. Las casas tenían tres aberturas por piso: en la planta baja, la puerta y dos ventanas; y en la superior, el balcón central y una ventana a cada lado. El edificio se remataba con un frontón y cornisa y la cubierta era construida con tejas. El exterior debía decorarse al fresco y con una pequeña voluta encima de las puertas y las ventanas. El 3 de febrero de 1753 se colocó la primera piedra, que marcaba el comienzo de la edificación del barrio.

En consecuencia, la Barceloneta fue, en cuanto a sus formas estéticas, un ejemplo del urbanismo barroco, como también de la expresión espacial de los intereses concordantes de las clases dominantes en la Barcelona de fines del siglo xviII: la naciente burguesía mercantil e industrial y el centralismo representado por las autoridades militares. Los intereses de ambos explican la localización del nuevo barrio. Este sirvió, de un lado, para organizar los servicios del área portuaria, instalar las actividades artesanales e industriales que la ciudad amurallada rechazaba y dotar de 
alojamiento a la población creciente que se dedicaba a tareas relacionadas con el mar y la incipiente industria. Por otro lado, el barrio se localizó allí donde podía ser más fácilmente controlado por la Ciutadella ante una eventual revuelta ciudadana antiborbónica.

Así pues, a mediados del siglo XIX una buena parte del espacio urbanizado de la Barceloneta estaba ocupada por establecimientos industriales. Su proximidad al puerto y a la primera línea del primer ferrocarril que se construyó en España, fuera de las murallas, hizo de la Barceloneta un lugar ideal para la instalación de las nuevas industrias: la Maquinista Terrestre y Marítima, la Nueva Vulcano, Talleres Alexander o Talleres Escuder. En consecuencia, los obreros buscaron su residencia en la Barceloneta por proximidad con sus puestos de trabajo en momentos en que los servicios públicos de transportes eran muy deficientes. La población se multiplicó por cinco y, como consecuencia, se autorizó ampliar las viviendas construyendo uno y dos pisos más en altura. Igualmente, la continuada necesidad de más viviendas llevó a que las casas se dividieran horizontalmente en dos, dando lugar a las casas de un cuarto de superficie. Así, de la superficie inicial de 140 metros cuadrados, las viviendas de la Barceloneta se redujeron a 35 metros cuadrados. Todos estos cambios contribuyeron a aumentar el efecto de estrechez de las calles y de vivir con sensación de congestión debido al gran número de familias que allí residían. Paralelamente se instauraron los baños de mar y la plaza de toros (El Torín, hoy desparecida), marcando el carácter que tendría el barrio.

La Guerra Civil (1936-1939) y el período de posguerra supusieron una época de olvido y retroceso del barrio. Con la llegada de los ayuntamientos democráticos, dos eventos de relieve internacional, los Juegos Olímpicos de 1992 y el Fórum de las Culturas de 2004, impulsaron a la ciudad a recuperar su frente marítimo y transformar de nuevo el espacio urbano: del barrio marinero e industrial al barrio gastronómico, de ocio nocturno y de reclamo turístico.

La remodelación urbanística surgida a raíz de los Juegos Olímpicos se basó en tres decisiones importantes: el saneamiento y la consolidación del litoral, el levantamiento de las líneas ferroviarias de la costa y la construcción de la ronda del litoral. El objetivo fue relacionar íntimamente el litoral con los vecinos e integrarlo a la ciudad como un espacio más de uso público. Con esta remodelación aparecieron también los primeros establecimientos hoteleros en el barrio. Así, se evidencia que los planes de renovación urbana del barrio, de mejora de la infraestructura pública, encubren los verdaderos objetivos de una dinamización económica sustentada en el potencial turístico y la revalorización de zonas patrimoniales (Janoschka et al., 2013; Janoschka \& Sequera, 2014; Jones \& Varley, 1999; Makhlouf, 2013; Salinas, 2013).

Por otro lado, la relevancia de la gastronomía de la Barceloneta nació en los pequeńos restaurantes frecuentados por los trabajadores del puerto y de las industrias, para luego devenir populares por el resto de barceloneses. En la playa había numerosos merenderos, originados a raíz de los muchos marineros que ofrecían cocina de pescador con el pescado fresco recién llegado del mar. Estos "chiringuitos" desaparecieron en los años noventa, siendo sustituidos por nuevos y modernos restaurantes. En la actualidad también se ha construido un puerto deportivo de lujo (Marina Port Vell, inaugurado no sin polémica), para el cual se conservó la dársena, 
la Torre del Reloj y el muelle de pescadores, aunque reduciendo notablemente sus dimensiones y visibilidad.

Ahora bien, el aumento de visitantes paralelo a los desarrollos mencionados ha desatado un notable sentimiento de turismofobia, una oposición que se ciñe básicamente a dos motivos: los problemas que plantean los pisos turísticos (sobre todo ilegales) y los conflictos de convivencia entre los vecinos y los turistas (principalmente nocturnos).

En este contexto se sitúa la Barceloneta, uno más de los barrios históricos dentro del distrito de Ciutat Vella, que incluye El Born, La Ribera, el Barrio Gótico y el Raval.

FIGURA I | Distritos municipales de Barcelona

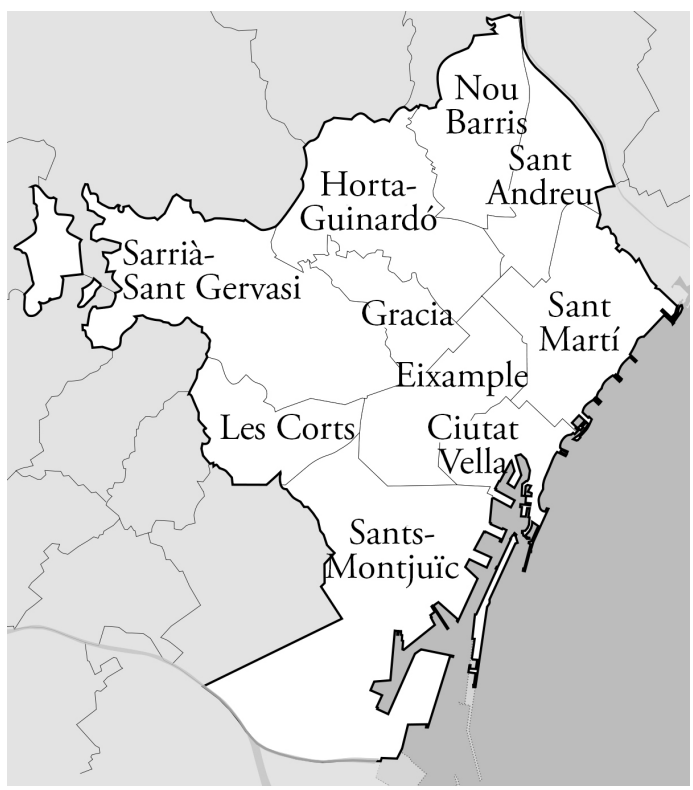

FUENTE AYUNTAMIENTO DE BARCELONA. EN HTTPS://ES.WIKIPEDIA.ORG/WIKI/DISTRITOS_DE_ BARCELONA

\section{Metodología}

Para analizar los parámetros de la transformación de la Barceloneta se tienen en cuenta fuentes hemerográficas y documentos públicos, los que permiten reseguir su evolución y cambios urbanos. Posteriormente se analizan datos de fuentes secundarias en cuanto a la actividad turística de Barcelona, uso de las playas, alojamiento, ocupación laboral y población en la Barceloneta. La observación participante y la opinión de vecinos implicados (ocho participantes) permiten interpretar con profundidad y detalle la situación del barrio a partir de entrevistas individuales y semiestructuradas. Su elección sigue criterios de representatividad y conocimiento del sector turístico, social y urbano: representantes de la plataforma de vecinos afectados por el turismo (2), responsables del Muelle de Pescadores (2) y 
restauradores (4). Las preguntas engloban aspectos relacionados con la situación actual del turismo; con las afectaciones sociales, culturales y urbanas de la actividad turística; la pérdida de identidad del barrio; los cambios que favorecen los turistas y la dinamización económica; y las repercusiones sociodemográficas de todo ello en el barrio. También entrevistas a turistas (10), elegidos aleatoriamente, ofrecen información acerca de su percepción respecto de los atractivos del barrio. En este caso, las preguntas van dirigidas a su satisfacción en cuanto a las infraestructuras y servicios públicos del barrio, y a la oferta de alojamiento, recursos culturales, gastronómicos y de ocio.

Todas las sesiones mencionadas tuvieron lugar entre los días 7 de septiembre y 15 de noviembre de 2016, con una duración máxima de sesenta minutos, tiempo para recoger las opiniones de los participantes y considerar una eventual saturación de la información. Finalmente, se abordó el estudio de los documentos, planes estratégicos y de usos de la administración local y estudios de otros académicos (Abril-Sellarés \& Alamilla, 2016; Azpilicueta \& Sánchez-Fernández, 2015) sobre la satisfacción de los residentes.

\section{Análisis de la estructura turística de la Barceloneta y de sus impactos}

El turismo en Barcelona no ha dejado de crecer. La transformación de la Barceloneta, en cuanto a los atractivos turísticos y la oferta de alojamiento, ha contribuido a ello. Los principales motivos de su popularidad apuntan a sus playas y su zona de gastronomía y ocio, con bares, restaurantes, terrazas al aire libre y discotecas que atraen no solo a los visitantes de paso, sino también a los propios habitantes de la ciudad.

La demanda turística no es estacional; se mantiene a lo largo del año, si bien es evidente que se intensifica en los meses de verano, cuando la playa es más atractiva, el clima más favorable y se dispone de más tiempo de ocio. Según el informe "Playas de BCN" (Ajuntament de Barcelona, 2016), entre mayo y septiembre de 2012 el número de turistas que visitaron las playas de la Barceloneta fueron, para la playa del Somorrostro, 630.483; para la Barceloneta, 435.333; y Sant Sebastià, 469.109 visitantes, que en total suman más de un millón y medio de bañistas solamente en las playas del barrio de la Barceloneta. Estas cifras dan una idea del poder de atracción que tiene la playa sobre el turista urbano.

TABLA I | Evolución de la ocupación de las playas de Barcelona (2008-2015)

\begin{tabular}{|l|c|c|c|c|c|}
\cline { 2 - 6 } \multicolumn{1}{c|}{} & $\mathbf{2 0 0 8}$ & $\mathbf{2 0 1 0}$ & $\mathbf{2 0 1 2}$ & $\mathbf{2 0 1 4}$ & 20I5 \\
\hline Mayo & 190.000 & 427.000 & 359.500 & 135.836 & 499.586 \\
\hline Junio & 500.000 & 637.000 & 874.068 & 892.396 & 1.012 .060 \\
\hline Julio & 775.000 & 1.112 .000 & 1.022 .621 & 1.221 .243 & 1.383 .947 \\
\hline Agosto & 735.000 & 937.000 & 1.167 .192 & 1.080 .322 & 1.231 .115 \\
\hline Setiembre & 290.000 & 343.000 & 329.492 & 473.488 & 612.564 \\
\hline TOTAL & 2.490 .000 & 3.446 .000 & 3.752 .873 & 3.802 .641 & 4.739 .270 \\
\hline
\end{tabular}

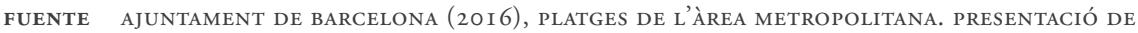
RESULTATS 20 I 6 [INFORME PLAYAS AMB] 
Por su parte, la gastronomía es el otro atractivo de la Barceloneta y está muy bien representada. El mercado de abastos de la Barceloneta, de carácter marinero, tiene más de 130 años de historia y alberga dos restaurantes de alta calidad. Según la tipología de mercados de Crespi-Vallbona y Domínguez (2016), se trata de un mercado sostenible, de uso tradicional para los residentes y reclamo turístico para los visitantes temporales. Hay que ańadir los otros 122 restaurantes, bares y tabernas emblemáticos. Algunos restaurantes ofrecen menús marineros con visitas guiadas a la Cofradía de Pescadores y el muelle. Todo ello ha ido acompañado del incremento de la oferta de alojamiento de la zona. Así, según los datos del Departamento de Empresa y Conocimiento de la Generalitat de Catalunya, el alojamiento en la Barceloneta consta de 2.936 plazas turísticas para un barrio de 15.036 habitantes (2015), con una superficie de $1,3 \mathrm{~km}^{2}$.

TABLA 2 Tipología de alojamiento en la Barceloneta

\begin{tabular}{|c|c|c|c|c|}
\hline $\begin{array}{c}\text { NOMBRE DEL } \\
\text { ESTABLECIMIENTO }\end{array}$ & MODALIDAD & CATEGORÍA & $\begin{array}{c}\text { NÚMERO DE } \\
\text { HABITACIONES }\end{array}$ & $\begin{array}{l}\text { NÚMERO DE } \\
\text { PLAZAS }\end{array}$ \\
\hline W Barcelona & Hotel & Gran Lujo & 470 & 940 \\
\hline Arts & Hotel & Gran Lujo & 455 & 1.012 \\
\hline Pullman Barcelona Skipper & Hotel & 5 estrellas & 230 & 482 \\
\hline 54 Barceloneta & Hotel & 3 estrellas & 20 & 36 \\
\hline Marina Folch & Hotel & 1 estrella & 10 & 19 \\
\hline $\begin{array}{l}\text { Residencia Universitaria Campus } \\
\text { del Mar }\end{array}$ & Albergue & & 126 & 135 \\
\hline Equitypoint & Hostal & & 15 & 121 \\
\hline Apartements Freestanza & Apartamento & & 4 & 10 \\
\hline Vivienda de uso turístico & Particular & & 72 & 165 \\
\hline TOTAL & & & & 2.936 \\
\hline
\end{tabular}

En estos datos oficiales no aparecen aquellas viviendas de uso turístico ilegal, de las cuales es muy difícil obtener una cifra exacta. Según datos del Ayuntamiento, del informe del impacto del alquiler vacacional en el mercado de alquiler residencial de Barcelona (2016, pp. 32-33), la proporción de viviendas de alquiler turístico supone un 5,7\% del total de viviendas disponibles (212/3719), resultando una ratio poco significativa para la reiterada intensidad turística ilegal. No obstante, en 2015 se registró un total de 201 denuncias de pisos de alquiler turístico ilegales en el barrio (Archivo de noticias del Ayuntamiento de Barcelona, 2016). Paralelamente, desde la plataforma de vecinos La Barceloneta diu prou (La Barceloneta dice basta) se afirma que el 35\% del total de viviendas de uso turístico tiene carácter ilegal.

Los principales intermediarios turísticos que actúan en el barrio de la Barceloneta pertenecen al sector del alojamiento y lo hacen a través de portales web. Algunos, como Booking o Hostelworld, están centrados en la reserva de hoteles, mientras que otros, como Airbnb, se centran en el alquiler de pisos turísticos, sean 
legales o ilegales. Por ejemplo, una de estas plataformas de alojamiento reticular (Russo \& Quaglieri, 2014), Airbnb, consta de 67 plazas de alojamiento entero, 61 habitaciones privadas y 3 compartidas. Este tipo de oferta actúa a través de portales web dedicados al alquiler de viviendas para uso turístico, lo que provoca un desequilibrio de su uso entre residentes y visitantes.

De la tipología de alojamiento descrita y los precios de sus habitaciones se puede colegir que el $80 \%$ de turistas tiene un nivel adquisitivo alto; un $9 \%$ tiene un nivel adquisitivo bajo, puesto que se alojan en albergues, hostales y hoteles de una estrella. Se supone que el $11 \%$ restante tiene un nivel medio, puesto que pueden escoger entre viviendas de uso turístico y hoteles de tres estrellas. Al parecer, en su gran mayoría las plazas hoteleras del barrio están destinadas a un turismo elitista de alto poder adquisitivo. Sin embargo, el comportamiento de algunos de los turistas nocturnos no está acorde con los estándares sociodemográficos descritos. Se corresponde a un perfil de turista de masa individual en busca de sol y playa, según la tipología que describe Cohen (1972), siendo su principal motivación la recreativa y de distracción. Este tipo de turista tiende a gastar básicamente en alojamiento. Además, suele planificar el viaje por su cuenta, evitando intermediarios, haciendo uso de redes sociales y plataformas electrónicas. Según las estadísticas de turismo de Barcelona, en el año 2015 más del $60 \%$ de turistas visitaba la ciudad por motivos de ocio y la franja de edad más frecuente entre ellos iba de los 25 a los 34 años (Ajuntament de Barcelona, 2015). Este dato es muy significativo, ya que coincide en algunos parámetros con lo que es el perfil de turista de "sol y playa", que viaja también motivado por la oferta del ocio. Y esta es la combinación de visitantes habituales en la Barceloneta.

Así pues, se observa que los turistas que causan molestias en el barrio son predominantemente jóvenes que buscan fiesta y alcohol, lo que provoca un cambio de actitud en sus conductas, que se hacen incívicas, con actos vandálicos (orinar en la zona pública, insultar, ir medio desnudo, etcétera), lo que provoca inseguridad e incomodidad a los vecinos. De esta forma, Alamilla (2016, p. 6) muestra que el $87,5 \%$ de los residentes encuestados considera que el consumo de alcohol en el barrio ha aumentado exponencialmente, por lo que un $59,6 \%$ opina que hay mucha más delincuencia. Se trata de jóvenes que buscan ocio nocturno, de los cuales no se distingue entre turistas y locales. Según Alamilla, el mencionado incivismo, el turismo de borrachera, el ruido, la suciedad, las conductas antisociales, el no descanso, la desnudez y la presencia de tiendas abiertas 24 horas para la venta de alcohol, así como la venta ambulante en las playas, son los motivos centrales de la turismofobia de los vecinos de la Barceloneta. También manifiesta que el incremento del ruido es el segundo impacto negativo que perciben los vecinos que viven en la Barceloneta, en un $77 \%$ de los encuestados. En pro de ello, las ciudades se hacen eco de la contaminación acústica, principalmente nocturna, asociándose al Réseau Européen "Vivre la Ville!" (red europea de asociaciones nacionales y regionales contra el ruido en la ciudad), que promociona un sello de calidad acústica e impulsa campañas de sensibilización. Barcelona también se ha unido a esta red. Sus resultados son meramente testimoniales. 
El turismo representa la segunda actividad económica del barrio, con una ocupación del 26,4\% (2015). Antes de la ola turística se disfrutaba de una equilibrada oferta de servicios básicos y tradicionales, como panaderías, carnicerías, peluquerías o tiendas para animales domésticos; hoy, estos han sido paulatinamente reemplazados por establecimientos que se orientan a la oferta de productos y servicios principalmente turísticos, como tiendas de souvenirs, bares de tapas o tiendas de alquiler de bicicletas, segways, patinetes y otros. Esta excesiva dependencia de la actividad económica y comercial del sector turístico causa un progresivo abandono de las actividades indispensables para la economía básica del barrio. Muchos de los negocios tradicionales han cerrado debido a los altos precios de los alquileres de los locales y a la irrupción de grandes empresas internacionales y nacionales que se han situado en la zona (McDonalds, Inditex, Desigual, Pans \& Company, etcétera). Así, el comercio vinculado al turismo y a las grandes cadenas prolifera, en detrimento del comercio tradicional del barrio, que se va desmantelando.

Tanta actividad repercute en la inflación de los precios de los bienes, principalmente de los inmuebles. Los precios abusivos de los alquileres de las viviendas y de los locales comerciales están directamente relacionados con la demanda del turismo. En efecto, el valor de los cuartos de casa en la Barceloneta ha subido de 540,71 euros, en el primer trimestre del año 2014, a 601,40 euros en el último trimestre de 2016 (Gabinete Técnico de Programación del Ayuntamiento de Barcelona). Por un apartamento de cuarto de casa de $30 \mathrm{~m}^{2}$, si se destina a piso turístico, se cobra 1000 euros por 10 días, o 3000 euros al mes. Muchos de los pisos que se ofrecen en el mercado turístico son de los propios residentes, que dejan su vivienda en el período de vacaciones y la alquilan a los visitantes temporales de la ciudad, con lo que perciben una retribución muy notable. Esta situación lleva a que cuando termina un contrato de alquiler de residentes, se pida por su renovación un gran incremento de la cuota mensual lo que obliga a que sus moradores dejen esa vivienda y busquen arrendar en otro barrio. Así, Abril-Sellarés y colaboradores (2015) señalan que la preocupación principal de los vecinos de la Barceloneta es la subida en los precios de los alquileres. La rentabilidad de los cuartos de casa como viviendas de uso turístico es muy superior a la de un alquiler convencional, dado que el público al que van dirigidos y su poder adquisitivo son muy distintos.

Buena parte de los residentes de la Barceloneta viven de alquiler (703 alquileres registrados en 2015, según datos del Anuario Estadístico, Gabinete Técnico de Programación, 2016), algunos de los cuales sufren diversas situaciones de mobbing por parte de los propietarios, que así persiguen echarlos para cambiar de negocio, de particulares a turistas. Se podría decir que el envejecimiento de la población que ocupa este tipo de vivienda en régimen de alquiler, todavía con renta antigua -es decir, con precio congelado-, ha sido sustituida (no necesariamente desplazada) por turistas, retirándose estas viviendas del parque de alquiler convencional de la ciudad. Por ello, Alamilla (2016) percibe que la gentrificación no es señalada como un problema, puesto que las personas que se van del barrio lo hacen a gusto, dado que les han pagado una buena cantidad de dinero por sus pisos. Además, como comentan los vecinos, la gente siempre se ha ido del barrio, desde antes de que hubiese turismo. Una de las principales razones es que los pisos son pequeńos, por 
lo que no se puede formar una familia con muchos hijos. En definitiva, como reitera Alamilla, existen opiniones diversas ante el fenómeno turístico en la Barceloneta, pues -según los resultados- un 39\% de los residentes se considera neutral y un 37\% a favor del turismo. Estos resultados indican opiniones divididas en cuanto al odio y/o estima hacia el turismo. Como afirman Zhou, Zhang, Zhang y Ma (2015, p. 31), la percepción de los residentes siempre es "subjetiva, relativa a los sentimientos, intuitivos e incluso, irracionales".

En cualquier caso, la resistencia a la gentrificación se fortalece e institucionaliza. El año 2014 nació un movimiento vecinal con el objetivo de denunciar las molestias causadas por la "turistización". Las manifestaciones llevaban como nombre simbólico La Barceloneta no es ven (La Barceloneta no se vende), que denota el descontento de la población local por el número excesivo de apartamentos destinados a uso turístico. La Barceloneta diu prou (La Barceloneta dice basta) -como ya se dijo- es el nombre de esta plataforma, que periódicamente sigue manifestando su descontento con el turista y que forma parte de la Asamblea de Barrios por un Turismo Sostenible (АВТS) de Barcelona. La plataforma vecinal denuncia no solamente los ruidos, el desgaste de las áreas comunales en las fincas y la falta de higiene por las calles, sino también, y sobre todo, la especulación inmobiliaria y la expulsión de la población local del barrio. El eco en la prensa es constante (La Vanguardia, 2014; El Mundo, 2015; El País, 2014, 2016).

Todo lo anterior está modificando negativamente el estilo de vida de los locales. El constante control de usos de los pisos del barrio por parte de los vecinos, listos a denunciar los establecimientos ilegales, repercute sobre la vida social del barrio, haciendo que los residentes se conviertan en policías y se forme una atmósfera de desconfianza general que destruye el sentimiento de comunidad en la Barceloneta, tan arraigado ańos antes de la turistización. El diseńo urbano del barrio permite ("obliga") el disfrutar y tener vida al aire libre en una proporción más elevada que en otros barrios de la ciudad. Ello se debe a la propia atmósfera de sus calles estrechas y de sus viviendas de $35 \mathrm{~m}^{2}$, con pocas o nulas ventanas que dejen entrar la luz y el aire necesario para ventilar la casa. Por ello, algo tan propio de la cultura mediterránea, como es vivir al aire libre durante el día y la noche, tiene un valor muy significativo en el barrio; un valor especial y obligado por las propias condiciones de las viviendas y del trazado urbanístico. Estas costumbres de convivencia social han marcado la comunidad, tejiendo importantes lazos de amistad, cooperativismo y fraternidad. Sin embargo, esta apacible convivencia está viviendo momentos disruptivos. La aglomeración de visitantes y la invasión de la actividad y los servicios turísticos han transformado esta convivencia en el momento en que los vecinos se convierten en los propios enemigos, al acecho de los pisos turísticos ilegales. Asimismo, el Ayuntamiento ha iniciado una campaña de sensibilización dirigida a los turistas para informar, desalentar y denunciar los alojamientos ilegales ("You-I-Bcn. Let's share Barcelona").

Junto a esta sonora turismofobia (puesto que la turismofilia es silenciosa) nace el interés por el patrimonio de la Barceloneta. Se han conservado y recuperado espacios de interés cultural, como edificios, plazas, entre otros, siendo la escultura del Negro de la Riba o la Casa Barceloneta algunos de los ejemplos destacados. El 
turismo constantemente busca integrarse en las costumbres y tradiciones del destino al que viaja, tal y como refleja Alamilla (2016, p. 7), según quien un 51,9\% de los residentes encuestados considera que la llegada de turistas garantiza la conservación de sus tradiciones.

Así, el contrapunto es el visitante. Según indican los turistas encuestados, su satisfacción es notablemente alta en su estancia y/o visita al barrio. Ella se basa en la fluida conexión con el centro mediante transporte público; en la oferta de alquiler de medios de transportes turísticos (bicicletas, motos, patinetes eléctricos, segways, skateboards) y la variedad de puestos de restauración y precios; y el estado y servicios de sus playas. No obstante, manifiestan un total desconocimiento de la existencia de oferta cultural. Esta baja valoración de la oferta cultural se debe a su escasa promoción y señalización. El Museo de Historia de Cataluña (MHC) fue inaugurado en 1996 con el objetivo de promover el conocimiento y la difusión de la historia y la cultura catalanas, aunque el porcentaje mayoritario de sus visitas corresponde a centros escolares. La Fiesta Mayor de la Barceloneta es otro hito cultural. Se celebra alrededor del 29 de setiembre, ya que San Miguel es el patrón del barrio, con ruas del famoso cañón, havaneras y correfocs. Las calles se engalanan y se hacen concursos para premiar a la mejor decorada. Sin embargo, la participación turística es meramente residual.

Otro emblema es la Casa Barceloneta, una casa histórica, recuperada para mostrar los inicios urbanísticos y arquitectónicos del barrio, pero su rotulación y sus explicaciones solo están en lengua catalana y no se difunde su existencia. Ciertamente la casa tiene un alto valor emocional, social y cultural para la comunidad de vecinos, y también podría tener interés para el turista.

\section{Conclusiones y propuestas: modelo de (re)conversión turística gentrificada}

Este estudio pretende reflexionar ante un fenómeno global: la actividad turística y la consecuente transformación urbana y social de los territorios donde tiene lugar. El caso estudiado -el barrio de la Barceloneta, en el distrito de Ciutat Vella de Barcelona- ofrece luces al respecto y sugiere actuaciones de gestión y gobernanza, vehiculando ambos usos e intereses: los cotidianos y funcionales de los residentes locales, y los de carácter ocioso y turístico de los visitantes temporales. Se apuesta por dar valor al patrimonio cultural tangible e intangible que abunda en el barrio, pero que hoy pasa desapercibido e ignorado; se apuntan soluciones ante los aspectos que más resentimiento y conflicto generan entre los vecinos.

El análisis de la Barceloneta pone de relieve los procesos de transformación urbana desarrollados desde la administración local, buscando la rehabilitación y mejora pública de los espacios e infraestructuras, en aras al desarrollo del potencial turístico. Así, en la actualidad, las playas de la Barceloneta, la oferta de alojamiento, restauración y ocio nocturno han incrementado el número de visitantes y residentes. Los síntomas de agotamiento y madurez que se viven en la Barceloneta se perciben con extrema proporción: la saturación; la estacionalidad, básicamente vacacional y en los meses de julio y agosto; el alojamiento colaborativo u hospitalidad reticular (en ocasiones descontrolada o ilegal); la aglomeración de bares y restaurantes que 
usurpan las calles y plazas en detrimento del comercio tradicional y el incivismo. Los procesos de gentrificación se han desencadenado en el barrio.

Frenar (y erradicar) el monocultivo y la turismofobia candente precisan de una intervención pública y política inmediata. Conciliar los usos del barrio para ambos usuarios, vecinos y visitantes, es un reto y una obligación. Compatibilizar los espacios es un proceso complejo y lento que requiere una colaboración directa y constante entre la administración local, la población y los visitantes al barrio. De aquí la recomendación de una conversión turística gentrificada. Si no se redirecciona, si no se corrige el modelo turístico vigente, la actual afluencia y la dinámica de la actividad turística en la Barceloneta contribuirán a su propia desaparición, destruyendo su encanto, su esencia. La turismofobia ganará la partida.

En aras a buscar una respuesta a la tensión que genera el turismo, el vigente Plan Estratégico de Turismo 2020 impulsa el proceso participativo de la ciudadanía sobre el modelo turístico de Barcelona y el desarrollo responsable. En esta misma línea trabaja el Plan de Desarrollo Económico de Ciutat Vella, distrito en el que se encuentra la Barceloneta. Por tanto, la Administración acentúa las medidas de información y, principalmente, de inspección y sanción para controlar el número de plazas hoteleras y de las viviendas turísticas.

No obstante, caben medidas más severas. Si bien las intenciones existen, la rigurosidad en la aplicación de los controles resulta ineficiente, al menos sobre los apartamentos turísticos ilegales y las horas de cierre de los locales de ocio nocturno. Asimismo, las multas no tienen una cuantía suficientemente elevada que disuada al propietario de repetir la infracción. Por ello, se debe establecer un plan de usos específico de la Barceloneta, con apoyo especial a los comercios tradicionales y a las inversiones locales, y garantizar una equilibrada distribución de los comercios; dar soporte activo al pequeño comercio local y de productos básicos en vez de permitir solo el enfoque turístico, el monocultivo. Ciertamente, en esta línea, el Plan de Usos del Distrito de Ciutat Vella regula las actividades que se generan (de restauración, de comercios de alimentación y de alojamiento), delimitando zonas donde la instauración de nuevas actividades es muy restrictiva, otras en la que la implantación es intermedia y, por último, zonas más permisivas. En cuanto a los pisos turísticos, el recién aprobado Plan Especial Urbanístico de Alojamientos Turísticos (PEUAT) ordena y controla el alojamiento turístico de Barcelona, garantizando los derechos fundamentales de los habitantes de la ciudad, y establece también una zonificación de alojamiento. Esta incluye la zona 1, de decrecimiento -en Ciutat Vella, parte del Eixample, Poblenou, Vila Olímpica, Poble Sec, Hostafrancs y Sant Antoni-, en que no se podrán abrir nuevos alojamientos aunque cierren otros; la zona 2 , de congelación -solo podrán abrir nuevos si cierran actuales-; y las zonas 3 y 4, de crecimiento limitado. La restricción en la Barceloneta es, pues, absoluta. 
FIGURA 2 Zonas de alojamiento turístico en las que queda dividiva Barcelona tras la aprobación del Plan Especial Urbanístico de Alojamientos Turísticos (PEUAT)

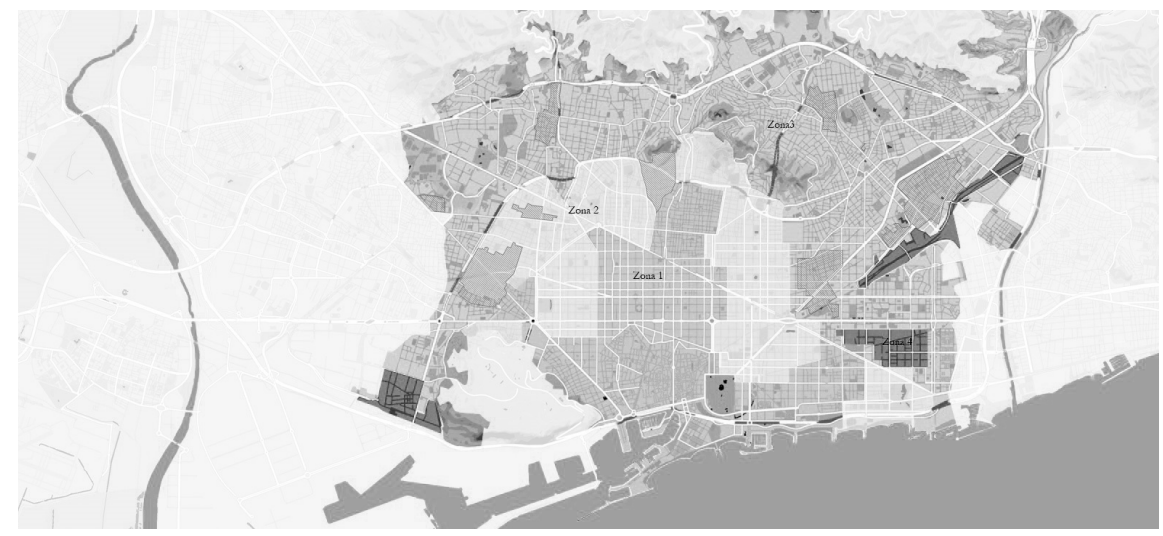

FUeNTE AYUNTAMiENTO DE BARCELONA, PEUAT, 20I7. EN HTTP://AJUNTAMENT.BARCELONA.CAT/PLAALLOTJAMENTS-TURISTICS/ES/

Sin embargo, la limitación de las licencias de pisos turísticos y el cierre de los ilegalmente establecidos no esconde la real preocupación de los residentes: el fin de las rentas antiguas o el incremento de las cuotas de alquiler. En una economía libre de mercado, el precio se determina por la concurrencia de la oferta y la demanda. La antigua política proteccionista franquista aprobó la Ley de Arrendamientos Urbanos (1964), que permitía tres subrogaciones de alquiler con prácticamente el mismo precio. Con ello, el mercado del alquiler de viviendas se congeló durante sesenta años, y los propietarios difícilmente podían mejorar sus inmuebles y pagar los impuestos que gravaban la propiedad. La reforma Boyer o nueva Ley de Arrendamientos Urbanos (1995) liberalizó el mercado de alquiler de viviendas y de locales de negocio y permitió pactar el tiempo de duración, la prórroga y el precio. Así, hoy los propietarios pueden modificar los alquileres, y algunos optan por el alquiler turístico. Controlar e imponer su legalidad, el pago de la tasa turística y de los impuestos que genera esta actividad es una tarea de la administración. Se insiste, pues, en el incremento del peso de las inspecciones y de las sanciones, así como el control del pago de los impuestos sobre los beneficios. En definitiva, no acompańar o apoyar la economía colaborativa y participativa, no legislar para su encaje en la ciudad turística, no representa un buen análisis de las tendencias del turismo por parte del gobierno actual (Lu \& Kandampully, 2016; Möhlmann, 2015).

En cuanto a la preocupación debida al incivismo, las molestias y los ruidos nocturnos, los altercados y las borracheras, se propone que para fomentar y garantizar la convivencia ciudadana la Ordenanza (2005) dote realmente de los medios coercitivos y punitivos necesarios para que las normas de convivencia señaladas se cumplan. Por ello, se precisa una partida presupuestaria específica para un plan de vigilancia de la guardia urbana (turística), con mayores dotaciones de personal y amplios horarios de vigilancia para hacer posible esta convivencia y sancionar al 
infractor con importantes penalizaciones (incrementando las vigentes). Esta medida modificaría el comportamiento de los visitantes en materia de urbanidad, civismo y conducta social.

Por otro lado, las políticas y estrategias de la administración no han apostado por su "autenticidad patrimonial". Así, del mismo modo en que se debe regular y legitimar unas determinadas formas de actuación empresarial, se debería potenciar y difundir una cultura de protección de la identidad del barrio y de la comunidad a través de la información y la sensibilización dirigidas a los propietarios de los pisos turísticos, a los vecinos del barrio y a toda la ciudad de Barcelona. También es necesario crear y potenciar espacios culturales o de interés científico para la atracción de diferentes tipos de población local y extranjera. Estos espacios suponen un cambio para la oferta, diversificándola y atrayendo a otro segmento de mercado diferente al actual, con nuevos intereses e inquietudes. Ejemplo de ello es la Casa Barceloneta, cuyas exposiciones son una buena herramienta pedagógica para forjar el interés y estima por el patrimonio cultural tangible e intangible del barrio. Se trata de un recurso cultural tanto para los locales como los turistas, puesto que su valor pedagógico es doble. Para los habitantes de la Barceloneta es un espacio para impulsar y educar a los vecinos residentes en relación con la historia y origen del barrio. Proyectar las exposiciones temporales en roll-ups para que se conviertan en museos nómadas y visiten otros centros culturales, bibliotecas y escuelas, ayudaría a compartir el conocimiento y educar en valores de colaboración con otros barrios y otras entidades, devolviendo al residente el carácter abierto, hospitalario, que ha ido perdiendo con el paso del tiempo y el turismo. Al turista, poder visionar, por ejemplo, un audiovisual sobre la historia de la Barceloneta, le ayudaría a concebir de otra forma el espacio urbano que está visitando y reflexionar sobre la transformación sufrida.

La Torre del Reloj es el ícono simbólico del barrio, pero inaccesible para el público. Ciertamente, este antiguo faro se halla en el Muelle de los Pescadores y tiene un alto valor patrimonial, tanto tangible como intangible, por ser una reminiscencia de los inicios del barrio. En este entorno, la creación de un espacio peatonal y abierto con un museo etnográfico vivo para mostrar el oficio del pescador, del redero, daría un valor ańadido y diferenciado a la actual oferta de la Barceloneta. Los rederos son actualmente marineros jubilados que mantienen su oficio por falta de voluntarios. Proyectar esta recuperación y valoración de los oficios del mar permitiría fortalecer el orgullo de las pocas familias que resisten en la pesca e impulsar su crecimiento, evitando su deterioro. No en vano, las familias de pescadores que quedan en el barrio son muy pocas, y muchos de los marineros son inmigrantes africanos y latinoamericanos. Organizar talleres participativos para los visitantes, locales y extranjeros, de aprendizaje de estos oficios en vías de desaparición del barrio, aseguraría la transmisión del patrimonio y del saber a las generaciones futuras.

Sustituir (relegar) el turismo de borrachera, de low-cost, sería posible si se señalizan e identifican los nuevos espacios culturales a que aludimos. Para este nuevo enfoque de gestión y reconversión del barrio es imprescindible que la experiencia turística del visitante incluya las tradiciones y la cultura. La cabina de información turística recientemente inaugurada y las rutas guiadas también ayudarían a ello. En definitiva, planificar un desarrollo de la oferta cultural del barrio diversificaría los 
atractivos y también el interés y el perfil del turista. Se iniciaría el proceso de elitización turística del barrio. Sin su patrimonialización, el sentimiento de comunidad se esfumará.

Cabe hacer hincapié en que este fenómeno turismofóbico no es exclusivo de la Barceloneta. Otros barrios de la ciudad (Raval, Sant Antoni, Gràcia, Sants o Poble Nou) han experimentado su disconformidad frente a la usurpación de su espacio cotidiano, con más o menos intensidad, e igualmente con plataformas de participación ciudadana.

\section{Referencias bibliográficas}

Abril-Sellarés, M., Azpilicueta, C. \& Sánchez-Fernández, C. (2015). Turismo sostenible: lugareńos frente a turistas. El caso de la ciudad de Barcelona. Holos, 3(31), 331-337. doi:http://dx.doi.org/10.15628/holos.2015.2809

Ajuntament de Barcelona (2007). Barcelona barri x barri. El nou mapa de barris de la ciutat. Barcelona: El Periódico de Catalunya.

Ajuntament de Barcelona (2015). Estadístiques de Turisme. Barcelona: ciutat i entorn. Barcelona: Barcelona Turisme. http://bit.ly/2keNxtr

Ajuntament de Barcelona (2016). Platges de L'àrea Metropolitana. Presentació de resultats. Del 16 de maig a 18 de setembre de 2016. [Informe Playas AMB]. Barcelona: Ajuntament de Barcelona, Departament d'Estudis d'Opinió Gabinet Tècnic de Programació. http:// bit.ly/2CQXh3N

Alamilla Canto, C. (2016). Análisis de los impactos socioculturales desde la perspectiva del residente que el turismo genera en el barrio de La Barceloneta, Espańa. Rotur. Revista de Ocio y Turismo, (11), 1-11. https://doi.org/10.17979/rotur.2016.11.1.1776

Alari, E. (2014). El barrio no se vende. Las barriografías de la Barceloneta como herramienta de resistencia vecinal frente al extractivismo urbano. Ecología Politica, (48), 36-41. https://dialnet.unirioja.es/servlet/articulo?codigo $=4933373$

Ayuntamiento de Barcelona (2016). Anuario estadístico. Barcelona: Gabinete Técnico de Programación. http://www.bcn.cat/estadistica/castella/dades/anuaris/anuari16/index. htm

Ayuntamiento de Barcelona (2016). Plan Estratégico de Turismo de Barcelona 2020. Diagnosis estratégica. Barcelona: Dirección de Turismo, Gerencia de Empresa y Turismo. http:// bit.ly/2CTOf6W

Ayuntamiento de Barcelona (2017). Plan Especial Urbanistico de Alojamientos Turísticos (PEUAT). Barcelona: Dirección de Turismo, Gerencia de Empresa y Turismo. http:// bit.ly/2BCX9Imhttp://ajuntament.barcelona.cat/ecologiaurbana/es/con-quien-lohacemos/participacion-ciudadana/alojamientos-turisticos

Beauregard, R.A. (1985). Politics, ideology and theories of gentrification. Journal of Urban Affairs, 7(4), 51-62. https://doi.org/10.1111/j.1467-9906.1985.tb00094.x

Bourdieu, P. (1997). La economía de los bienes simbólicos. En P. Bourdieu, Razones prácticas. Sobre la teoría de la acción (pp. 159-198). Barcelona: Anagrama. 
Butler, R. W. (1980). The concept of a tourist area cycle of evolution: implications for management of resources. The Canadian Geographer/Le Géographe Canadien, 24(1), 5-12. https://doi.org/10.1111/j.1541-0064.1980.tb00970.x

Butler, R. W. (2000). Tourism and the environment: A geographical perspective. Tourism geographies, 2(3), 337-358. https://doi.org/10.1080/14616680050082553

Carrión, F. (2010). El laberinto de las centralidades históricas en América Latina. Quito: Ministerio de Cultura.

Casgrain, A. \& Janoschka, M. (2013). Gentrificación y resistencia en las ciudades latinoamericanas. El ejemplo de Santiago de Chile. Andamios - Revista de investigación social, 10(22), 19-44. https://doi.org/10.29092/uacm.v10i22.265

Certeau, M. (1990). Linvention du quotidien I, Arts de faire. París: Gallimard.

Chatterton, P. \& Hollands, R. (2003). Urban nightscapes: Youth cultures, pleasure spaces and corporate power. Londres: Routledge / Psychology Press.

Clark, G. \& Chabrel, M. (2007). Measuring integrated rural tourism. Tourism Geographies: An International Journal of Tourism Space, Place and Environment, 9(4), 371-386. https:// doi.org/10.1080/14616680701647550

Cohen, E. (1972). Toward a sociology of international tourism. Social Research, 39(1), 164182. http://www.csus.edu/indiv/s/shawg/courses/182/articles/cohen/cohen.pdf

Crespi-Vallbona, M. \& Domínguez-Pérez, M. (2016). Los mercados de abastos y las ciudades turísticas. Pasos. Revista de Turismo y Patrimonio Cultural, 14(2), 400-416. http://www. redalyc.org/articulo.oa?id=88145251007

Desmond, M. (2012). Eviction and the reproduction of urban poverty. American Journal of Sociology, 118(1), 88-133. https://scholar.harvard.edu/files/mdesmond/files/desmond. evictionpoverty.ajs2012.pdf

El Mundo (2015). http://www.elmundo.es/cataluna/2015/05/22/555f7bd3268e3e95348b45 9c.html

El Pais (2014). https://elpais.com/ccaa/2014/08/20/catalunya/1408562737_343739.html

El País (2016). https://elpais.com/ccaa/2016/09/06/catalunya/1473154551_325825.html

García, F. (2016). Compacidad y densidad de las ciudades españolas. EURE, 42(127), 5-27. http://dx.doi.org/10.4067/S0250-71612016000300001

González, S. (2011). Bilbao and Barcelona 'in motion'. How urban regeneration 'models' travel and mutate in the global flows of policy tourism. Urban Studies, 48(7), 1397-1418. https://doi.org/10.1177/0042098010374510

Guerrero, R. (2012). Patrimonio cultural mundial, territorio y construcción de ciudadanía. Construcción y apropiación social del patrimonio cultural de la ciudad de ValparaísoChile. Scripta Nova, Revista Electrónica de Geografía y Ciencias Sociales, 16(388). http:// www.ub.edu/geocrit/sn/sn-388.htm

Gwiazdzinski, L. (2007). Nuits d'Europe. Pour des villes accessibles et hospitalières. Chantiers: Université de Technologie de Belfort-Montbéliard (UтвM). http://bit.ly/2AD54BL

Harvey, D. (1989). From managerialism to entrepreneurialism: The transformation in urban governance in late capitalism. Geografiska Annaler. Series B, Human Geography, 71(1), 3-17 https://doi.org/10.1080/04353684.1989.11879583

Heller, A., (1998). Sociología de la vida cotidiana. Barcelona: Península. 
Hiernaux, D. (2006). A reapropriaçâo de bairros da Cidade do México pelas classes médias: em direçâo a uma gentrificaçâo. En C. Bidou, D. Hiernaux \& H. Rivière (eds.), De volta à cidade: dos processos de gentrificaçâo às políticas de revitalizaçâó dos centros urbanos (pp. 229-264). Sâo Paulo: Annablume.

Janoschka, M \& Sequera, J. (2014). Procesos de gentrificación y desplazamiento en América Latina: una perspectiva comparativista. En J. J. Michelini (ed.), Desafios metropolitanos. Un diálogo entre Europa y América Latina (pp. 82-104). Madrid: Catarata.

Janoschka, M., Sequera, J. \& Salinas, L. (2013). Gentrification in Spain and Latin America - a critical dialogue. International Journal of Urban and Regional Research, 38(4), 12341265. https://doi.org/10.1111/1468-2427.12030

Jones, G. \& Varley, A. (1999). The reconquest of the historic centre: Urban conservation and gentrification in Puebla, Mexico. Environment and Planning A, 31(9), 1547-1566. https://doi.org/10.1068/a311547

La Vanguardia (2014). http://www.lavanguardia.com/vida/20140119/54399287987/turismodispara-precio-pisos-barceloneta.html

Lees, L., Slater, T. \& Wyly, E. (2008). Gentrification. Londres: Routledge.

Liu, Z. (2003). Sustainable tourism development: A critique. Journal of Sustainable Tourism, 11(6), 459-475. http://dx.doi.org/10.1080/09669580308667216

López, M. \& Grau, R. (1971). Barcelona entre el urbanismo barroco y la revolución industrial. Cuadernos de Arquitectura y Urbanismo, (80), 28-40. http://www.raco.cat/index.php/ CuadernosArquitecturaUrbanismo/article/view/111032

López-Morales, E. (2011). Gentrification by ground rent dispossession: The shadows cast by large-scale urban renewal in Santiago de Chile. International Journal of Urban and Regional Research, 35(2), 330-357. http://dx.doi.org/10.1111/j.14682427.2010.00961.x

Lu, C. \& Kandampully, J. (2016). What drives customers to use access based sharing options in the hospitality industry? Research in Hospitality Management, 6(2), 119-126. http:// dx.doi.org/10.1080/22243534.2016.1253276

Makhlouf, N. (2013). Aproximaciones a un movimiento vecinal en La Barceloneta, Barcelona. Transformaciones urbanas desde la resistencia. Buenos Aires: Facultad de Ciencias Sociales, Universidad de Buenos Aires.

Martínez, G. (2008). Barcelona rebelde: guía histórica de una ciudad. Barcelona: Random House Mondadori.

Möhlmann, M. (2015). Collaborative consumption: Determinants of satisfaction and the likelihood of using a sharing economy option again. Journal of Consumer Behaviour, 14(3), 193-207. http://dx.doi.org/10.1002/cb.1512

Nelle, A. (2009). Museality in the urban context: An investigation of museality and musealization processes in three Spanish-colonial World Heritage Towns. Urban Design International, 14(3), 152-171. https://doi.org/10.1057/udi.2009.15

Padin, C. (2012). A sustainable tourism planning model: Components and relationships. European Business Review, 24(6), 510-518. https://doi. org/10.1108/09555341211270528

Plog, S.C. (1974). Why destination areas rise and fall in popularity. Cornell Hotel and Restaurant Administration Quarterl, 14(4),55-58.https://doi.org/10.1177/001088047401400409 
Portillo, A. (1988). Ciudad y conflicto: un análisis de la urbanización capitalista. Montevideo: Ediciones Deltaller.

Ritchie, J. R. \& Crouch, G. I. (2003). The competitive destination: A sustainable tourism perspective. Londres: Cabi.

Ritzer, G. (1996). Classical sociological theory. Nueva York: McGraw-Hill.

Russo, P. \& Quaglieri, A. (2014). La lógica espacial del intercambio de casas: una aproximación a las nuevas geografías de lo cotidiano en el turismo contemporáneo. Scripta Nova, Revista Electrónica de Geografia y Ciencias Sociales, 18(483). http://www.ub.edu/ geocrit/sn/sn-483.htm

Salinas, L. (2013). Gentrificación en la ciudad latinoamericana. El caso de Buenos Aires y Ciudad de México. Geographos, 4(44), 281-305. https://doi.org/10.14198/ GEOGRA2013.4.44

Saxena, G., Clark, G., Oliver, T. \& Ilbery, B., (2007). Conceptualizing Integrated Rural Tourism, Tourism Geographies: An International Journal of Tourism Space, Place and Environment, 9(4), 347-370. http://dx.doi.org/10.1080/14616680701647527

Sharpley, R. (2000). Tourism ans Sustainable Development: Exploring the Theoretical Divide. Journal of Sustainable Tourism, 8(1), 1-19, http://dx.doi. org/10.1080/09669580008667346

Sobarzo, M. (2008). Gubernamentalidad patrimonial. Revista de Diseño Urbano y Paisaje (DU\&P), 5(13) [Universidad Central, Santiago de Chile].

Tatger, M. (1973). La Barceloneta del siglo XVIII al Plan de la Ribera. Barcelona: Ediciones Saturno.

Vergara, C. \& Casellas, A. (2016). Políticas estatales y transformación urbana: hacia un proceso de gentrificación en Valparaíso, Chile. EURE, 42(126), 123-144. http://dx.doi. org/10.4067/S0250-71612016000200006

Weber, R. (2002). Extracting value from the city: Neoliberalism and urban redevelopment. Antipode, 34(3), 519-540. http://dx.doi.org/10.1111/1467-8330.00253

World Tourism Organization (wто). (2004). Indicators of Sustainable Development for Tourism Destinations: A Guidebook. Madrid: wTо.

Yunis, E. (2004). Sustainable tourism and poverty alleviation. Bruselas/Madrid: World Tourism Organization. http://www.tanzaniagateway.org/docs/sustainable_tourism_and_poverty_ alleviation.pdf

Zhou, Q., Zhang, J., Zhang, H. \& Ma, J. (2015). A structural model of host authenticity. Annals of Tourism Research, (55), 28-45, https://doi.org/10.1016/j.annals.2015.08.003 